\title{
AOR
}

Selected Papers of \#AoIR2018:

The $19^{\text {th }}$ Annual Conference of the

Association of Internet Researchers

Montréal, Canada / 10-13 October 2018

\section{MORE THAN MEETS THE EYES: THE LENS OF VISIBILITY IN INTERNET RESEARCH}

\section{Panel overview}

The objective of this panel is to examine the analytical and empirical relevance of the "visibility lens" for Internet research. Just over a decade ago, media researchers have started to take a specific interest in the constitutive role of mediated visibility in the organization of social reality. For example, Brighenti (2007) discussed the relevance of analyzing social phenomena through the lens of visibility as a unifying analytical category, positing its centrality in the sustainment of social processes such as recognition and control. For his part, Thompson (2005) defined visibility as a doubleedged sword to showcase how it can be weaponized as a useful tool to both gain power or cause harm. He also addressed how mediated visibility afforded by digital media technologies blurred the traditional boundaries between public and private life (Thompson, 2011). These reflections highlight the intricacies of in/visibility regimes. Indeed, being visible can be associated with the procurement of power, while being denied visibility can be the result of social exclusion. Alternatively, gaining unwanted visibility can constitute a liability, while remaining invisible can also be a privilege (Myles \& Trottier, 2017). Thus, the activation of selected in/visibilities must always be understood as being highly situated (Brighenti, 2007) and cannot be understood outside of the power dynamics that sustain it (Heinich, 2012; Voirol, 2005).

Since then, there has been an increasing interest in the concept of visibility within the field of Internet research. Studies have so far focused on the role of mediated visibility in relation to activist engagement, political mobilization, and public debate; Internet governance and policy-making; the constitution or disarrangement of publics; organizational transparency; emerging forms of gender and sexual identities; the legitimacy of work and professional identities; the production and sharing of knowledge and information; surveillance processes and related forms of vigilantism; and social relations and context collapse. Overall, studies have underlined the fundamental role of visibility afforded by digital media technologies in the social recognition or exclusion of individuals, groups, and communities. They have also identified visibility and its 
management as being constitutive of social identities, relations, and practices among actors in a variety of fields.

Consequently, Internet researchers have so far provided various definitions and operationalizations of mediated visibility. For example, Yang (2016) defines visibility as a dual concept that can be apprehended as both a political lever for individuals and collectives, as well as a conceptual category for researchers to make sense of social reality. Mediated visibility is also frequently associated with digital materiality. As such, it is sometimes used as a criterion to categorize digital media technologies regarding the control they allow for users to manage and disclose personal contents or activities (Bregman \& Haythornthwaite, 2003; Cardon, 2008; Stenger \& Coutant, 2013). Furthermore, visibility is also conceptualized as an affordance that is enabled by the functionalities of digital media technologies and enacted through their situated uses (Bucher, 2012; Treem \& Leonardi, 2013).

In this panel, presenters are first invited to examine how visibility is mediated through digital media technologies by exploring a series of case studies on the social recognition of identity minorities, on the online presence of mundane work practices, on digital vigilantism, as well as on hackers and their practices of concealment. They are also encouraged to raise theoretical, methodological, and ethical issues linked to the conduction of such inquiries. Then, this panel seeks to draw similarities and contrasts between each case study, as well as to discus the implications and, indeed, the relevance of formalizing the lens of visibility in the field of Internet research.

\section{References}

Bregman, A., \& Haythornthwaite, C. (2003). Radicals of presentation: visibility, relation, and co-presence in persistent conversation. New Media \& Society, 5(1), 117-140.

Brighenti, A. (2007). Visibility: A category for the social sciences. Current sociology, 55(3), 323-342.

Bucher, T. (2012). Want to be on the top? Algorithmic power and the threat of invisibility on Facebook. new media \& society, 14(7), 1164-1180.

Cambridge: Polity Press.

Cardon, D. (2008). Le design de la visibilité. Réseaux, (6), 93-137.

Heinich, N. (2012). De la visibilité: excellence et singularité en régime médiatique. Gallimard.

Myles, D., \& Trottier, D. (2017). Leveraging Visibility, Gaining Capital? Social Media+ Society, 3(1), 2056305117691998.

Stenger, T., \& Coutant, A. (2013). Médias sociaux: clarification et cartographie Pour une approche sociotechnique. Décisions marketing, 107-117.

Thompson, J. B. (2005). The new visibility. Theory, culture \& society, 22(6), 31-51.

Thompson, J. B. (2011). Shifting boundaries of public and private life. Theory, Culture \& Society, 28(4), 49-70.

Treem, J. W., \& Leonardi, P. M. (2013). Social media use in organizations. Annals of the International Communication Association, 36(1), 143-189. 
Voirol, O. (2005). Les luttes pour la visibilité. Réseaux, (1), 89-121.

Yang, F. (2016). Rethinking China's Internet censorship: The practice of recoding and the politics of visibility. New Media \& Society, 18(7), 1364-1381.

\section{Digital Visibility and Power Struggles Among Identity Minorities: Can the Use of Social Media Sustain Agency?}

Mélanie Millette

Université du Québec à Montréal

In the past decade, digital media technologies like Facebook, Tumblr, or blogs have contributed to important changes in the landscape of communication, insofar as ordinary citizens and their online activities now have the potential to become massively visible. In the context of such mutations, this paper addresses the possibilities and constraints afforded by the Internet to citizens who wish to gain agency as political actors and increase the visibility of their demands, ideas, and beliefs through the use of social media platforms (Dahlberg, 2011). As Brighenti (2010) argues, visibility is embedded in power dynamics that effectively woven the social fabric. Visibility allows the creation of "objects", the opening of possibilities, as well as the fostering of new relationships. Its opposite - invisibility - can (but not always) annihilate possibilities for citizens and researchers alike, since "what is not seen is not thematized as an object in the domain of action" and the state of being "invisible is what is here without being an object" (Brighenti, 2007: 328).

Defined as such, the realm of visibility opens the scope of constructivism: the subjective ways of looking at oneself, the ways that objects or subjects become perceptible, and the shared significations that ensue are constitutive of social reality and contribute to producing and reproducing power dynamics. In turn, this underlines the importance of understanding visibility from a political perspective as it affects the ways in which "reality" is represented, decoded, and defined. During this presentation, we will examine the possibilities that visibility allows for identity minorities who acquire it by and for themselves. Specifically, we will ask: how can visibility foster or improve social recognition for minority groups of citizens and, ultimately, how can it develop agency (or fail to do so)?

In the literature, studies on alternative, community, or radical media have underlined the necessity of fostering new forms of visibility for individuals and collectives who have been excluded from dominant mass media (Fenton \& Peschanski 2007; Lievrouw 2011). As we will argue, social media platforms offer possibilities to minority groups to be "heard" in the public sphere, notably by participating to the constitution of counterpublics (Fraser, 1990), but also through an array of sociotechnical practices and strategies. At the intersection of social media studies (Millerand et al., 2010; Papacharissi, 2010; Proulx et al. 2012), of reflections on mediated visibility (Thompson, 2005; Voirol, 2005) and of critical analyses regarding the notion of "public sphere" (Fraser, 1990), we will address the power dynamics that are inherently linked to digital 
visibility among identity minorities and focus on how such visibility can potentially sustain agency.

To examine this phenomenon, we will draw from two empirical studies. First, we will present the results from a study conducted among French-Canadian groups outside of Québec that are part of communities whose identity, language, and culture are minoritized. We will specifically address how these communities invest social media platforms to express, claim, and legitimized their own identities. Second, we will draw from the preliminary findings of our current research on LGBTQ+ communities in Québec who also use social media platforms to formulate and vocalize political demands within the public sphere or, alternatively, to constitute safe spaces that allow their members to meet in restricted and controlled settings. In both case studies, we developed methods that rely on mixed data analysis, while keeping a resolutely qualitative stance. Drawing from ethnographic approaches, we performed ongoing online participant observation, extracted data on various social media platforms (publications, comments, tweets, etc.), and conducted individual interviews.

For this presentation, we will specifically underline the emerging similarities and contrasts between both studies' results, which reveal how the use of social media platforms now occupies a central place in the repertoire of everyday citizen actions that are mobilized to participate politically and to "exist" socially in contemporary societies. We will discuss the various "visibilizing" strategies used by collectives who either exploit or divert the affordances of social media platforms to attain their goals, like calling out elected officials and promoting a part of their identity publicly, on the one hand, or remaining invisible to foster social support and to freely express social, political, or cultural beliefs without the fear of being persecuted on the other. Indeed, our results suggest that being granted (unwarranted) visibility can also be associated with violence and oppression, which explains the development of ingenious strategies to segregate publics and generally manage digital visibility.

To conclude, this presentation will also argue that, in order to truly participate in the sustainment of agency among identity minorities, digital visibility must at least respect three criteria. First, visibility must be accompanied by sociotechnical competency, which refers to a technical, cognitive, and communicative know-how that allows individuals to master and craftily exploit social media platforms (among other digital media technologies). Second, digital visibility must take shape and be enacted within a specific collectivity or community. As such, individual uses of the Internet that result from a minority status sometimes aim to find common folks to meet personal socio-affective needs, while others sustain relational or associative goals. These endeavours can remain rather informal and take shape through the sharing of personal testimonials, or even formally result in political organizing (like the constitution of counterpublics). Third, for digital visibility to truly sustain agency, it must lead to a form of social recognition from the Other(s) (Honneth, 2005), by which we mean the individuals or collectives (may they be peers, elected officials, etc.) who are in a majority or dominant position. We argue that it is only when these three levels are experienced that digital visibility can 
positively be associated with the sustainment of agency among identity minorities. Ultimately, while our two case studies may focus on very different fields, both can help us illustrate the intricacies of the power dynamics that are inherently linked to digital visibility and its enactment in contemporary societies.

\section{References}

Brighenti, A. (2007). Visibility: A category for the social sciences. Current sociology, 55(3), 323-342.

Brighenti, A. M. (2010). Visibility in social theory and social research. Springer.

Dahlberg, L. (2011). Re-constructing digital democracy: An outline of four 'positions'. new media \& society, 13(6), 855-872.

Fenton, N. et Peschanski, J. A. (2007). Mainstream Media or Alternative Media ? In K. Coyer, T. Dowmunt, \& A. Fountain (Eds.), The Alternative Media Handbook (p. 141-162). London, New York: Routledge.

Fraser, N. (1990). Rethinking the public sphere: A contribution to the critique of actually existing democracy. Social text, (25/26), 56-80.

Heaton, L., Millette, M., \& Proulx, S. (2012). Médias sociaux: Enjeux pour la communication. PUQ.

Honneth, A. (2005). Invisibilité: sur l'épistémologie de la «reconnaissance». Réseaux, 1(129-130), 39-57.

Lievrouw, L. (2011). Alternative and Activist New Media. Cambridge, UK ; Malden, MA : Polity Press

Millerand, F., Proulx, S., \& Rueff, J. (Eds.). (2010). Web social: mutation de la communication. PUQ.

Papacharissi, Z. (2010). A private sphere: Democracy in a digital age. Polity.

Thompson, J. B. (2005). The new visibility. Theory, culture \& society, 22(6), 31-51.

Voirol, O. (2005). Les luttes pour la visibilité. Réseaux, (1), 89-121.

\section{Sharing and Accessing the Mundane Dimensions of Work on Social Media: The Role of Mediated Visibility for Workers and Researchers}

Claudine Bonneau

Université du Québec à Montréal

Viviane Sergi

Université du Québec à Montréal

Within the field of Internet studies, work, workers, and their mediated visibility have been examined either from the perspective of online surveillance, where workers' activities and communication practices are scrutinized by their employers (Fuchs et al., 2013), or from the perspective of self-branding, where visibility is the result of an explicit strategy among individuals that involves the "calculated use of social media" to gain "status and attention online" (Duffy, 2017: 11) in order to showcase their potential and employability (Hogan, 2010; Pagis \& Ailon, 2017). But the visibility of work is also 
constructed by individuals who voluntary share the mundane and daily experience of their professional life on social media platforms, not only for the sake of promoting themselves, but also to experience, legitimatize, and criticize their own work. As we will argue in this presentation, there is much to be gained by examining what can be perceived as the 'mundane' experience of individuals at work. Contrarily to commonly held ideas, mundanity is much more consequential than it appears. As we have argued elsewhere: "it is there that skills are developed and tested, that ideas are crafted and progressively brought to light, that solutions are devised, adjusted and deployed, that knowledge is gained, that reflexivity is sharpened and that a full spectre of emotions may be experienced" (Sergi \& Bonneau, 2017).

Our initial observations led us to identify and flesh out the concept of "Working Out Loud", which we define as a communicative and sociomaterial practice where individuals voluntarily turn to social media platforms to narrate and show what is part of their daily work life (Bonneau \& Sergi, 2017; Sergi \& Bonneau, 2016, 2017). While this specific practice can be observed on enterprise social media (ESM), which are corporate versions of social media platforms that are designed only for internal audiences, we argue that 'extra-organizational' platforms (such as Facebook, Twitter, and Instagram) should also be examined. Indeed, such platforms allow researchers and professionals alike to observe emerging practices that are not prescribed by an organization, as well as unseen aspects of more conventional occupations that do not necessarily require the use of digital technologies (like farmers, bakers, etc.).

Our work is inspired by Alcadipani and Islam (2017)'s approach which investigates materiality through visual images. In this stage of our research, we focus on Instagram, which is primarily a visual social networking site (Highfield \& Leaver, 2016). Our methods rest on a qualitative 'small/thick data' approach (Latzko-Toth et al., 2017) based on digital ethnography during which we performed the manual collection of a small corpus of 150 public Instagram posts. We considered posts as "holistic units" (Laestadius, 2017) where images/videos, texts, emoji, and hashtags are to be interpreted together and thematically coded in an open and inductive manner.

At the heart of our inquiry lies the idea that people use social media platforms to share material (like thoughts, impressions, experiences, moods, etc.) that not only relate to their personal life, but also to their working life. While researchers have so far had to "be there' and spend time in a specific organization to develop a sense of its mundane fabric, nowadays working out loud practices that take place on social media platforms give us access to organizational life and to the environment in which work unfolds, alongside its spatial and material setup. Such practices showcase the unfinished and 'behind-the-scene' aspects of work, like ongoing work processes and work in progress. They also materialize and publicize dimensions of work (affective, expressive, embodied, and aesthetic) that have so far been mostly intangible. 
Furthermore, working out loud also makes visible what has traditionally been regarded as 'invisible work' (Hatton, 2017; Star \& Strauss, 1999). Invisible work may refer: a) to backstage work taking place in spaces that are usually not accessible to other people than the ones performing the same tasks in close proximity, b) to "informal work processes that are not part of anybody's job description but which are crucial for the collective functioning of the workplace" (Nardi \& Engeström, 1999: 1), or c) to professional activities that are not formally recognized or that are devalued as being not really 'work'. The 'visibilizing power' of working out loud - that is, how it can increase visibility - can indeed be efficiently put to use in cases where workers are invisibilized or marginalized, by eventually granting them legitimacy or recognition. Hence, this presentation will specifically address the role of mediated visibility in the study of mundane work for both the workers who share their subjective experience at work, as they are seeing it and choosing to expose it online, and the researchers who study such discursive-material assemblages.

As our results will show, the mediated visibility afforded by social media platforms to mundane work practices sustains shared reflexivity among actors and contributes to constructing and legitimizing professional identities. For researchers who study contemporary organizations and work practices in the digital age, a careful examination of the ordinary, daily experience of life at work is far from banal, as it offers a novel and relevant entry point to study a variety of organizational phenomena. In a context where work and organizations are undergoing significant changes, and where boundaries between work and non-work activities are blurred, our results show the importance of exploring how mundane aspects of work are expressed in new ways on social media platforms. Finally, we will conclude this presentation by addressing the theoretical and methodological implications of pursuing such inquiries.

\section{References}

Alcadipani, R., \& Islam, G. (2017). Modalities of opposition : Control and resistance via visual materiality. Organization, 1-26.

Bonneau, C., \& Sergi, V. (2017). Work-related image sharing on Instagram : implication for the understanding of social media affordance of visibility. In Piet Kommers (Ed.), Proceedings of the International Conference ICT, Society, and Human Beings 2017 (pp. 226-230). Lisbon, Portugal.

Duffy, B. E. (2017). (Not) Getting Paid to Do What You Love: Gender, Social Media, and Aspirational Work. Yale University Press.

Fuchs, C., Boersma, K., Albrechtslund, A., \& Sandoval, M. (2013). Internet and surveillance: The challenges of Web 2.0 and social media. Routledge.

Hatton, E. (2017). Mechanisms of invisibility: rethinking the concept of invisible work. Work, Employment and Society, 31(2), 336-351.

Highfield, T., \& Leaver, T. (2016). Instagrammatics and digital methods: Studying visual social media, from selfies and GIFs to memes and emoji. Communication Research and Practice, 2(1), 47-62.

Hogan, B. (2010). The presentation of self in the age of social media: Distinguishing performances and exhibitions online. Bulletin of Science, Technology \& Society, 
30(6), 377-386.

Laestadius, L. (2017). Instagram. In A. Quan-Haase \& L. Sloan (Eds.), The SAGE Handbook of Social Media Research Methods (pp. 573-592). Sage.

Latzko-Toth, G., Bonneau, C., \& Millette, M. (2017). Small Data, Thick Data: Thickening Strategies for Trace-based Social Media Research. In A. Quan-Haase \& L. Sloan (Eds.), The SAGE Handbook of Social Media Research Methods (pp. 199-214). Sage.

Nardi, B. A., \& Engeström, Y. (1999). A web on the wind: The structure of invisible work. Computer Supported Cooperative Work, 8(1), 1-8.

Pagis, M., \& Ailon, G. (2017). The Paradoxes of Self-Branding: An Analysis of Consultants' Professional Web Pages. Work and Occupations, 44(3), 243-267.

Sergi, V., \& Bonneau, C. (2016). Making mundane work visible on social media: a CCO investigation of working out loud on Twitter. Communication Research and Practice, 2(3), 378-406.

Sergi, V., \& Bonneau, C. (2017). As I see life at work: sharing work experiences on social media. In 33rd EGOS Colloquium, Sub-theme 61: Viewing the Unseen Organization in Practice. Copenhagen, Denmark.

Star, S. L., \& Strauss, A. (1999). Layers of Silence, Arenas of Voice : The Ecology of Visible and Invisible Work. Computer Supported Cooperative Work, (1995), 9-30.

\section{3. "We Speak Out, We Make Ourselves Visible, and We Act!" Vigilantism and The Constitutive Role of Online Visibility}

David Myles

Université de Montréal

Daniel Trottier

Erasmus University

Based on Myles \& Trottier (2017), the objective of this presentation is to further examine the role of online visibility in the emergence of vigilante initiatives by drawing from a Canadian case study. Founded in 2015, The Judge Beauce is a vigilante collective that claims to address Québec's "flexible laws" for child protection by identifying potential pedophiles through physical and online surveillance. Today, vigilante groups increasingly use the Internet to conduct their daily activities (Huey et al., 2013). So far, traditional definitions of vigilantism have considered the use of force as a defining feature (Johnston, 2001), while few studies have addressed how social media features that afford visibility (Bucher, 2012; Treem \& Leonardi, 2012) partly reconfigure vigilante actions and identities (Trottier, 2016a).

Our presentation shows how online visibility is leveraged by vigilante groups not only to direct public attention toward suspects, but also to create, engage with, and solicit support from "affective publics" (Papacharissi, 2014) that become increasingly sensitized to child safety. Furthermore, it examines the relation between online visibility and the procurement of "policing capital" (Dupont, 2004) by underlining how social 
media platforms allow new ways to acquire various forms of symbolic and material resources.

This presentation relies on the qualitative analysis of various data that were extracted online (from November 2015 to January 2016) and converted into a PDF format manually. Our dataset includes: 1) screen captures from an online blog called La Clique du Plateau (119 comments) and from the online forum Reddit (14 comments); 2) eight news articles, as well as one radio and one television interviews with The Judge's founder; 3) screen captures of The Judge's official website; and 4) contents from The Judge's Facebook page (the equivalent of 60 pages).

Our results first show that leveraging online visibility was key for The Judge to procure economic capital, which refers to the "monetary resources" possessed by a policing entity (Huey et al., 2013: 83). Economic capital was accumulated through the online sale of merchandise bearing the collective's logo (a skull with intersecting bones) or slogan (Let's protect our kids). Rooted in the microeconomic model of crowdfunding (Belleflamme et al., 2014), this strategy facilitated the procurement of funds that were allegedly used to finance activities. Yet, the adoption of such model required for the Judge to expose their fundraising activities to public criticism and, as such, also appeared to be a liability. Indeed, many users expressed their disapproval on the collective's Facebook page, stating that this type of commercial endeavour was disrespectful toward victims of abuse.

Leveraging online visibility was also key in the procurement of social capital, what Dupont (2004: 86) defines as the "social relations that allow the constitution, maintenance and expansion" of policing entities. For The Judge, social capital was closely linked to economic capital, as the sale of merchandise also allowed for the creation of vigilant publics. Members invested social media platforms to openly endorse the collective by publishing pictures of themselves wearing The Judge merchandise. Hence, our results point to a "weaponization of visibility" through acts of intimidation toward suspected pedophiles. This is a departure from other forms of self-justice that leverage online visibility to punish actions (via doxing or public shaming) that are perceived as being transgressive while enjoying a position of anonymity (Trottier, 2016b).

Our case study also underlines how online visibility allowed for The Judge to gain political capital. Traditionally, political capital refers to the "ability to influence public policy and use government resources" (Huey et al., 2013: 84) and understands State proximity as being exclusively positive. Yet, our results point to a form of capital procurement that operates under a logic that is more horizontal than vertical. Indeed, as a grassroot initiative, the case of The Judge shows that political capital can be acquired by constituting affective publics (Papacharissi, 2014) and not solely through proximity with the political sphere. Not only was the lack of proximity with the State unproblematic; it was also instrumentalized by The Judge's members who stated that politicians did not 
address child safety seriously and that it was up to citizens to act by harnessing the "power of crowds" (McCosker, 2015).

Finally, leveraging online visibility was linked to the procurement of cultural capital, which refers to "the explanatory and actionable knowledge" that a policing entity "can mobilize, at the individual and collective levels" (Dupont, 2004: 86). In our case study, we examined how The Judge's members publicly expressed conceptions of social reality based on shared beliefs, as well as how they identified the correct ways to act upon these beliefs. Our results show the importance of two interrelated beliefs: 1 ) popular views (rather than evidence- or practice-based knowledge) regarding child abuse that focus on the dangers that represent strangers lurking in public places; and 2) the importance of performing an active citizenship. This cultural capital was materialized online through visual and structural elements reminiscent of biker culture (the use of a "crest", the foundation of local "chapters", etc.). While the enactment of such cultural capital online allowed for The Judge to generate a network of like-minded individuals, it also proved to be a liability, as many Facebook users quickly associated the collective with organized crime.

While our case study shows that online visibility does allow new ways for vigilante collectives to acquire policing capital, it also demonstrates that, as a double-edged sword (Thompson, 2005; Brighenti, 2007), visibility is simultaneously linked with the public questioning of these organizations' intentions by concerned citizens. In shifting our focus away from the perspective that strictly considers visibility as a form of harm for surveillance targets, we begin to understand the benefits and liabilities brought on by mediated visibility for modern vigilante groups.

\section{References}

Belleflamme, P., Lambert, T., \& Schwienbacher, A. (2014). Crowdfunding: Tapping the right crowd. Journal of Business Venturing, 29, 585-609.

Brighenti, A. (2007). Visibility a category for the Social Sciences. Current sociology, 55, 323-342.

Bucher, T. (2012). Want to be on the top? Algorithmic power and the threat of invisibility on Facebook. new media \& society, 14(7), 1164-1180.

Dupont, B. (2004). Security in the age of networks. Policing and society, 14, 76-91.

Huey, L., Nhan, J., \& Broll, R. (2013). 'Uppity civilians' and 'cyber-vigilantes': The role of the general public in policing cyber-crime. Criminology and Criminal Justice, 13(1), 81-97.

Johnston, L. (2001). Crime, fear and civil policing. Urban Studies, 38, 959-976.

McCosker, A. (2015). Social Media Activism at the Margins: Managing Visibility, Voice and Vitality Affects. Social Media+ Society, 1(2), 1-11.

Myles, D., \& Trottier, D. (2017). Leveraging Visibility, Gaining Capital? Social Media Use in the Fight Against Child Abusers: The Case of The Judge Beauce. Social Media+ Society, 3(1), 2056305117691998. 
Papacharissi, Z. (2014). Affective publics: Sentiment, technology, and politics. Oxford University Press.

Treem, J. W., \& Leonardi, P. M. (2013). Social media use in organizations: Exploring the affordances of visibility, editability, persistence, and association. Annals of the International Communication Association, 36(1), 143-189.

Trottier, D. (2016a). Digital Vigilantism as Weaponisation of Visibility. Philosophy \& Technology, 1-18.

Trottier, D. (2016b). Social media as surveillance: Rethinking visibility in a converging world. New York: Routledge.

Thompson, J. B. (2005). The new visibility. Theory, Culture \& Society, 22, 31-51.

\section{Encrypted Beneath the Surface: Visibility and Its Background}

Nathalie Casemajor

Institut national de la recherche scientifique

Sophie Toupin

McGill University

Drawing from cultural studies and digital media studies, this presentation examines the dynamic relationship between forms of visibility and forms of concealment. Its premise is that the domain of the hidden, and the ways of (self)concealment, are constructed in synergy with the ways of perceiving, interpreting, judging, and tracking down that are specific to a given context and time. Each new concealment strategy creates an arsenal of tools for detection, which in turn generates new forms of concealment and visibility. Thus, the art of disguise evolves with the advancement of technology, but also according to the development of social norms and relations of power. To what extent does the metaphor of visibility/invisibility articulate with that of encryption/decryption? We will explore this articulation through the example of encryption technologies (especially steganography - the art of hiding information within an image file) and anticolonial hacking during the Apartheid period in South Africa.

Concealment can be understood as a central vector in the constitution of private and public spheres (Wolff, 1950). The contemporary world is criss-crossed by (seemingly) contradictory logics, where hypervisibility in the media intersects with conspiracy theories and beliefs in a hidden truth, further fuelled by the opacity of technological and financial infrastructures. Shaped by big data and ever-improving algorithms, the possibilities for detecting identities and behaviours have multiplied in the digital environment (Lyon, 2015). They have engendered resistance to profiling and surveillance through the extensive use of pseudonyms, message encryption systems as well as masks, make-up, and disruptive clothing aimed to deceive surveillance cameras and facial recognition software (Riisgaard \& Thomassen, 2016). As a strategy, hiding responds to a range of needs: to protect that which is sensitive, to retain a strategic advantage, to deceive, or to avoid social disapproval or sanctions. The tactics used are equally diverse. They may include making invisible (camouflaging; Brighenti \& Castelli, 2016), obscuring (creating confusion, diverting attention), revealing some parts in order 
to better hide what is essential (disguise, steganography, optical illusion; Forbes, 2011) or protecting access (cryptography, censorship, and self-censorship).

This tension between the desire to hide and to reveal provides a decisive key to the understanding of struggles for agency and the way they are enacted through relations of mutual anticipation. Our analytical framework combines a materialistic approach to media and digital infrastructures with elements drawn from semiotic and phenomenological approaches. This framework allows to examine mediatized visibility through the relationship between the visible surface and its background. From the 1950 s to the late 1980 s, several literary theorists engaged in a theoretical disagreement over a short story by Edgar Allan Poe, disputing the relationships between visibility, concealment, truth, and meaning (Muller \& Richardson, 1988). In The Purloined Letter (Poe, 1844), Detective Dupin criticizes the police for seeing "only their own ideas of ingenuity; and, in searching for anything hidden, advert only to the modes in which they would have hidden it." Furthermore, "to conceal this letter, the Minister had resorted to the comprehensive and sagacious expedient of not attempting to conceal it at all." Inspired by Poe's story, Lacan (1966) drew from it, in his "Seminar on The Purloined Letter", a reflection on truth, reality, the symbolic, and the unconscious, in which he argues that "what is hidden is never but what is missing from its place." Derrida, in The Purveyor of Truth, proposes a critique of Lacan by questioning the "psychoanalytic deciphering" through the metaphor of "the nakedness of hidden meaning." Equating veil, text, and fabric, he suggests that the same material simultaneously conceals and shows. This relationship between the visible surface and the "invisible lining" (MerleauPonty, 1968) situates visibility in relation to a background; but, as Larkin (2013: 336) points out, "what is background for one person is a daily object of concern for another".

Moving away from the literary and postmodernist discussion, we situate our analysis in the context of digital media and disguise strategies. On a technical level, this relationship between visible surface and concealment is well illustrated by the case of steganography, or "covered writing". Steganographic techniques allow to identify redundant bits in a cover digital image, select a subset of such bits and replace them with data from a secret message. In this case, the visual surface stands as a deceiving screen, hiding sensitive information in the background code of the image file (Forbes, 2011; Shell, 2012). On a social level, this articulation between visibility and concealment can be observed in hacking networks, as our presentation will underline. In particular, the use of cryptography, hacking, and phone phreaking techniques in anti-colonial struggle(s) allowed freedom fighters to communicate and organize secretly in their attempt to dismantle colonial and apartheid regimes. The steps that were necessary to configure both technologies and social realities for use in a specific context and underground situation was such that the articulation between visibility and concealment needed to be carefully thought through. Drawing from these case studies, we will propose to understand the notion of visibility in relationship with strategies of active concealment. The processes of encryption/decryption we analyze in these case studies show that the borders that delineate and define what is "the background" of the visible realm are always technically, socially, and historically situated. 


\section{References}

Brighenti, A. M., \& Castelli, A. (2016). Social camouflage: functions, logic, paradoxes. Distinktion: Journal of Social Theory, 17(2), 228-249.

Derrida, J., Domingo, W., Hulbert, J., \& Ron, M. (1975). The purveyor of truth. Yale French Studies, (52), 31-113.

Forbes, P. (2011). Dazzled and deceived: mimicry and camouflage. Yale University Press.

Lacan, J. (1966). Le séminaire sur la lettre volée. Écrits, 1, 19-75.

Larkin, B. (2013). The politics and poetics of infrastructure. Annual Review of Anthropology, 42, 327-343.

Lyon, D. (2015). Surveillance after Snowden. John Wiley \& Sons.

Merleau-Ponty, M. (1968). The visible and the invisible: Followed by working notes. Northwestern University Press.

Muller, J. P., \& Richardson, W. J. (1988). The Purloined Poe Lacan, Derrida \& Psychoanalytic Reading.

Poe, E. A. (1844). "The Purloined Letter," The Gift: A Christmas, New Year, and Birthday Present, Carey \& Hart.

Riisgaard, L., \& Thomassen, B. (2016). Powers of the Mask: Political Subjectivation and Rites of Participation in Local-Global Protest. Theory, Culture \& Society, 33(6), 7598.

Shell, H. R. (2012). Hide and seek: Camouflage, photography, and the media of reconnaissance. MIT Press.

Wolff, K. H. (1950). "The Secret and the Secret Society," in The Sociology of Georg Simmel, Glencoe, The Free Press, 301-378. 